\title{
Evaluation and Evaluation Index System of Community Home Care Service under the Government Purchase of Social Organizations
}

\author{
Tianyun Pei \\ Department of Economic Management \\ North China Electric Power University \\ Baoding, China \\ hdpeity@126.com
}

\begin{abstract}
In the case of a weakening of the family function and family in China to support the social background of the telephone, home care service evaluation system is our country home pension services development of the force at the core, to provide to provide scientific basis for evaluation. By combing the existing literature, it is found that the current home care service evaluation system is still at the initial stage, and the implementation of different places is different, the evaluation system has not set up a unified standard. In this paper, through the summary of the relevant literature, from home care service assessment system to build a theoretical basis, practical experience, and the sustainability of the three aspects of the progressive elaboration. Refer to the construction and implementation of the domestic and foreign system, from the service of the professional, standardized, and can be, the effectiveness of the assessment system in four areas, to build a complete logic of thinking.
\end{abstract}

Keywords-Component; Government Purchase Service; Home Care Service Evaluation; Service Evaluation; Service Evaluation Index System Construction; Evaluation Theory

\section{COMMUNITY HOME CARE SERVICE ASSESSMENT SUPPORT THEORY}

\section{A. Concept Definition}

The concept of community home care service evaluation is made up of two parts. First, home care services by Gao Lingzhi, Liu Xue (2012) explain the basic attributes of the public class services, is to provide services for the family and community service is an important social service, including providing projects and staff. [7] Zhang Zhonghua (2012) added that the government as the owner, social organizations, service agencies for the contractor, the contractor for the home care service.[8] Lv Xuejing (2009) that the participation of social organizations, make up for the government's service area, effectively aggregated pension resources. [9] Second, service evaluation by Li Zhicheng, Liu Manfeng (2003) gives an explanation, the evaluation content for the actual gain and the expected difference. The indexes can be divided to obtain, stable, timely, sure, accept, and calculate the weight, and draw the conclusion. Since then, Sun Wencan (2013) explained that pension service assessment is a comprehensive analysis and evaluation of the status of the elderly at the present stage of the old people in the situation of determining the actual needs and affordability and institutional services to provide capacity. [4] Zhang Xiaoyi, Mei Qiang (2012) and home care characteristics, to make a comprehensive concept interpretation, and considering the characteristics of public services in the community home care services, should take the performance evaluation theory to assess. [1] Simple terms, home care service assessment is based on the general public service characteristics, through scientific computing, the elderly satisfaction, institutional capacity assessment.

\section{B. assessment of theoretical differences}

TABLE I. ASSESSMENT OF THEORETICAL DIFFERENCES

\begin{tabular}{|c|c|c|}
\hline View & Unique content & Reference \\
\hline \multirow{2}{*}{$\begin{array}{l}\text { View } \\
\text { of the } \\
\text { unique } \\
\text { content } \\
\text { of the } \\
\text { literatu } \\
\text { re }\end{array}$} & $\begin{array}{l}\text { Considering social, profit, time, } \\
\text { equity, building the } 4 \mathrm{E} \text { model to } \\
\text { evaluate }\end{array}$ & $\begin{array}{l}\text { Zhang Xiaoyi, Mei } \\
\text { Qiang. Study on the } \\
\text { performance evaluation } \\
\text { index system of } \\
\text { community home care } \\
\text { service [J]. Statistics } \\
\text { and decision making, } \\
2012,24: 73-75 .\end{array}$ \\
\hline & $\begin{array}{l}\text { Attach importance to quality } \\
\text { management, service type, } \\
\text { service effective decentralization }\end{array}$ & $\begin{array}{l}\text { Lu Yiting Shanghai } \\
\text { home care service } \\
\text { evaluation system } \\
\text { construction [D]. } \\
\text { Shanghai Jiaotong } \\
\text { University }\end{array}$ \\
\hline $\begin{array}{l}\text { Quality } \\
\text { of } \\
\text { service } \\
\text { as the } \\
\text { core }\end{array}$ & $\begin{array}{l}\text { To service quality as the core of } \\
\text { customer service quality and } \\
\text { service expectations and } \\
\text { recognition of the degree of } \\
\text { difference between the feelings }\end{array}$ & $\begin{array}{l}\text { Zhang Xiaoyi, Liu } \\
\text { Bangcheng. The quality } \\
\text { of service for the aged } \\
\text { in the community at } \\
\text { home. The study of the } \\
\text { quality of service for the } \\
\text { aged in Shanghai City, } \\
\text { for example, [J]. China } \\
\text { Population Science, } \\
\text { 2011, 03:83-92+112. }\end{array}$ \\
\hline $\begin{array}{l}\text { With } \\
\text { service } \\
\text { time as } \\
\text { the } \\
\text { core }\end{array}$ & $\begin{array}{l}\text { Its service time as the core } \\
\text { evaluation theory of time }\end{array}$ & $\begin{array}{l}\text { sun man Chan. Pushing } \\
\text { the pension service } \\
\text { evaluation and improve } \\
\text { the quality of life of the } \\
\text { elderly [J] social } \\
\text { welfare } 2013,19-21\end{array}$ \\
\hline
\end{tabular}

C. Assessment Techniques

Now in the home care service assessment theory basis, domestic scholars broke through the previous qualitative and quantitative research, put forward a number of, network, and other mechanisms to build all kinds of assessment model as a home care service assessment technology theory. 
First, to evaluate the logical relationship of the data complexity, Liu Jing (2005) proposed a quantitative assessment. Because of the abstraction of the evaluation index, the evaluation results are analyzed with statistical theory, and the theory is tested. [4] Game clearly (2013) proposed network governance assessment will be more than one evaluation unit of the network, and the convergence, in the assessment of the implementation of the assessment of people's choice. In contrast, the latter through management skills and advanced digital communication to make in the network of government departments, private organizations and social groups, efficient cooperation. [6] Zhang Xiaoyi, Mei Qiang (2012) using the weight analysis for data calculation. Using the scientific method to calculate the weight of the assessment data, more recognition.

Second, the construction of evaluation model theory is also popular among scholars. Yang Hongyan (2001) using ADL index evaluation, in order to evaluate the index. Through the investigation of these items, it can reflect the change of the demand of the aged people in the same time, thus indirectly reflect the service ability of the agency. [11] Show that this model is from the needs of the elderly, dynamic, objective, true, no useless. And Yao Yilan (2014) study that, "P" (performance) and " $\mathrm{C}$ " for capacity (Capality) the comprehensive evaluation theory is "APC" evaluation theory, "a" means is accountability (accountability). [12] Due to the current assessment of home care services in most parts of our country, including the service recipient needs assessment, a small amount involved in the performance assessment, the home care service agencies to assess the accountability and organizational capacity is less and less. Therefore, to establish a scientific and comprehensive evaluation system, the "APC" evaluation theory is more reasonable.

\section{COMMUNITY HOME CARE SER VICE ASSESSMENT PRACTICE EXPERIENCE}

Home care service assessment includes the government's funds, government purchase mechanism, standard evaluation and service evaluation and so on. Chinese and foreign scholars have done a lot of research, made a lot of progress. In particular, many experiences have been gained in the local practice.

\section{A. Purchase Mechanism and Standards}

For the government purchase mechanism, the standard of assessment directly determines the service's commitment. Purchase mechanism, the quality of the standard and the future of the service ability directly linked to the agency. The assessment of the role should not be underestimated. Dong Hongya (2014) believes that the government to buy the mechanism should be open to the public, the purchase of the contents of the public, requiring public. Relaxation of the scope, enhance competitiveness. At the present stage, it is a lack of competition. [13] $\mathrm{Li}$ Kang (2001) to make a supplement to the competition, should follow a fair, open and efficient three principles. To exchange for the purpose of the commodity exchange, social organizations through the market bid to get the order, the maximum level of capital value. Combined with other policies, the realization of the image, corruption, social stability and other purposes. At the same time to enhance the visibility of the organization, creating power. [14]

\section{B. Service Content}

Home care service assessment of the core lies in the service. Services provided directly to the elderly themselves, and the quality of life of the elderly. Therefore, domestic and foreign scholars have made a further research on the service provision, and have made a series of progress.

Liu Bangcheng (2011), Zhang Xiaoyi () in the assessment of the design, the proposed use of household survey method, questionnaire method, design community home care service quality assessment dimension. In the implementation of the assessment, provide the "community home care service assessment design table" will serve to give the score, and through visits to the elderly, random checks, telephone access, to determine the skills of institutions and practitioners, to build the home care service object assessment table to avoid the assessment of the problem of randomness to make assessment content refinement. Build a professional assessment team to promote the assessment of the fairness of the increase. Wan Yulong, Xie Jun (2014) proposed the use of the literature reading method, reference external regulations and other evaluation of the reference literature for objective evaluation. [15]

\section{HOME CARE SER VICE ASSESSMENT OF SUSTAINABLE} DEVELOPMENT

\section{A. Guarantee of Work Standardization}

Home care service assessment needs to be made under the strong security mechanism to achieve considerable development. First of all, according to the Ministry of civil affairs to promote the assessment of pension services to guide the views, the key words for the talent, the assessment of professional, financial diversification.

First, Yang Chunhua (2009) proposed concept of "standard": Center of the standardization of the service for the aged people to take the lead, to explore the full range, in theory and to establish a government in [16] secondly, Yao Yilan (2014) proposed four criteria of security: financial support; government subsidies and incentive policies; professionalism. These four points with a comprehensive, systematic and integrated approach to assess the practice of policy support for home care services is conducive to the smooth implementation of the assessment, it is worth taking. Once again, Chen Jing, Wen Xuan (2014) in order to guarantee the standardization of funds as an example, this paper proposes to expand the sources of funds, service enterprises. W.L. Lai Winglam, P.Y. Chan Jessica, K.K. Choi Pluto, C.T. Ngai Lilac, S.F. Mar Connie, Y.L. Chan Echo, Lam Pok, Y.P. Lam and Flora N.Y. (2009), Hongkong home care social service innovation: to encourage cooperation between social organizations. Development. [17]

\section{B. Method Innovation}

Sun Zeyu (2007) proposed the evaluation method, based on the evaluation results, the establishment of the agency to assess the agency, so that the staff of professional. Tongjiang Haixia [18], Chen Lei (2010) the, government supervision and complaint department open 
management and establish accountability system, the use of legal means to protect the interest of the audience, a check in the end. [19] Liu Bangcheng, Zhang Xiaoyi (2011) to build a service quality model, "exploratory factor analysis and assignment" and "confirmatory factor analysis", the score corresponding to the service. However, this method is more general and lack of maneuverability, and cannot be integrated with local conditions.

\section{SERVICE EVALUATION INDEX SYSTEM CONSTRUCTION AND INTERPRETATION}

According to the previous review, we can focus on the home care service assessment indicators focus on professional, standardized, and can be and effectiveness of the four goals.

\section{A. index construction}

TABLE II. HOME CARE SERVICE ASSESSMENT INDICATORS

\begin{tabular}{|c|c|c|c|}
\hline & first indexes & second index & third index \\
\hline \multirow{17}{*}{ Service } & \multirow{4}{*}{ professiona } & \multirow[b]{2}{*}{ team } & $\begin{array}{l}\text { qualification } \\
\text { certification }\end{array}$ \\
\hline & & & $\begin{array}{c}\text { Professional training } \\
\text { Practical operation } \\
\text { ability }\end{array}$ \\
\hline & & \multirow{2}{*}{ Equipment } & facilities environment \\
\hline & & & Professional service tool \\
\hline & \multirow{6}{*}{ Standard } & \multirow{3}{*}{ Procedure } & Procedure standard \\
\hline & & & Standard stability \\
\hline & & & $\begin{array}{l}\text { Key technical } \\
\text { specification }\end{array}$ \\
\hline & & \multirow{3}{*}{ Ceremonial } & dress \\
\hline & & & Language \\
\hline & & & Limbs \\
\hline & \multirow{3}{*}{ Accessibility } & \multirow{2}{*}{ Response } & Response time \\
\hline & & & Effective response \\
\hline & & Cost price & reasonable price \\
\hline & \multirow{4}{*}{ Effective } & \multirow{2}{*}{ subjective } & $\begin{array}{c}\text { service attitude } \\
\text { satisfaction }\end{array}$ \\
\hline & & & $\begin{array}{c}\text { Service quality } \\
\text { satisfaction }\end{array}$ \\
\hline & & \multirow[b]{2}{*}{ Objective } & complaints \\
\hline & & & $\begin{array}{c}\text { Random sampling } \\
\text { service expert } \\
\text { evaluation }\end{array}$ \\
\hline
\end{tabular}

\section{B. Index Interpretation}

In the first level, the service specialization refers to whether the institution has professional service qualification. Service standardization refers to whether the agency has a standard specification. Service availability and performance are the time and price of service provided by the service recipients.

Professional, personnel refers to the main staff, equipment and facilities, equipment, whether professional, through the main staff has professional certificate, experienced professional training, have the ability to assess the actual operation. Equipment and facilities for housing to meet the needs of the space, whether clean, the use of the tools of the service is professional.

Service standardization refers to whether the agency has a standard specification. Is the establishment of a standard service process, including the establishment of the standard work process, the staff of each operation and the key details are in accordance with the specifications. Etiquette evaluation refers to the establishment of standards in service etiquette. Including the service, the dress code, language, work behavior whether there is a uniform standard specification.

In service accessibility, responsiveness refers to the ability of service personnel to provide timely services. From the arrival of the old man waiting for the arrival of service personnel, service personnel are not effective solution to the needs of the two aspects of the evaluation. Whether the price of each service is evaluated in the old man's cost price.

Service validity refers to the quality of the results from the subjective and objective evaluation of the service. Subjective evaluation, including the satisfaction of the service staff attitude and service effect. Objective evaluation, by the experts and scholars to push the statistics of complaints, random sample service experts as the third party, the actual observation and service provision process, the service is an objective evaluation.

\section{Indicator Evaluation Method}

Evaluation method is divided into three categories, according to the characteristics of different regions, the score will be given reasonable weight, the final score.

First, the index is divided into 1 - 5 five levels, according to the actual situation of the staff of the organizations by experts were 1 -- 5 scoring, with higher scores, pension services more outstanding. Second, the experts randomly selected a staff to follow the service, according to the actual service conditions by the staff of the comprehensive score. Mainly divided into 1 -- 5 five grades, the higher the score, the better the effect of service. Third, randomly select a service receiver within the scope of coverage, the service recipient subjective scoring. Mainly divided into 5-5, 1 grades, the greater the number, the higher the degree of service recipients.

\section{REFERENCES}

[1] Zhang Xiaoyi, Mei Qiang, "Research on the performance evaluation index system of community home care service" [J] statistics and decision, 2012, 24:73-75.

[2] Zhang Xiaoyi, Liu Bangcheng, Research on the quality model of the community home care service -- Taking Shanghai as an example of $[\mathrm{J}]$. Chinese population science, 2011,03:83-92+112.vv

[3] Chen Jing, Wen Xuan. The practice of social organization in home care services $[\mathrm{J}]$. Journal of Guangxi University For Nationalities (PHILOSOPHY AND SOCIAL SCIENCES EDITION) 2014,01:43-47 
[4] Sun Pushing pension service man Chan evaluation[J], improve the quality of life of the elderly social welfare 2013,19-21

[5] Liujing. Urban community life cannot take care of themselves home care for the elderly life quality evaluation index system of exploration [J]. Journal of population studies, 2005, 01: 22-27.

[6] Race in the home care model in the perspective of network governance [J]. 2013,03:107-111.

[7] High glossy ganoderma, Liu Xue. Research on the urban home care service from the perspective of supply and demand [J]. Journal of Nantong University (SOCIAL SCIENCE EDITION), 2012, 03:63-73.

[8] Zhang Zhonghua. The thinking and practice of the old way of Chinese characteristics [M] Tianjin: Tianjin people's Publishing House 2009

[9] Lv Xuejing, China's non-profit organizations to participate in home care services research [D] Beijing: Capital University of Economics and Business, 2009

[10] Li Zhicheng, Liu Manfeng's "analysis and evaluation of service quality" (J) 2003 (03)

[11] Yang Hongyan. Assessment system for home care in the home care [J]. Market and population analysis, 2001, 03:61-66.

[12] Yao Yilan. Community home endowment service evaluation system and policy guarantee, Zhejiang Hangzhou Ningbo typical community survey $[\mathrm{J}]$ Shaoxing College of Arts and Sciences Journal of 2014,07:68-72

[13] Dong Ya. China's endowment service subsidy system origin and development path of Zhongzhou [J]. Journal, 2014, 08:82-86.

[14] Li Kang. Shanghai city on the exploration of government not buy service investigation and thinking of the $[\mathrm{J}]$ Chinese civil affairs decision version of 2001,06:23 - 25

[15] Ishida, Xie Jun "standard to establish endow ment service quality evaluation index system of scientific research" standard based on 2014 (06)

[16] Yang Chunhua. The plight of urban community home care and the way out [J]. 2009,08:161-163.

[17] Winglam W.L. Lai Jessica, P.Y. Chan, K.K. Choi Pluto, THERAPY Ngai Lilac, C.T. Connie, S.F. Mar Echo, Y.L. Chan Pok, Y.P. Lam N.Y. Lam and Flora OCCUPATIONAL INTEGRATED THE IN ELDERLY AND COMMUNITY SUPPORT SERVICES FOR THE ELDERLY IN HONG KONG [J] HKJOT 2009; 19 (1): 27 - 30

[18] Sun Zeyu. Thinking about the problems and Countermeasures of urban community home care service in our country $[\mathrm{J}]$. Journal of China Institute of Industrial Relations, 2007, 01:98-101.

[19] Hai Xia Jiang, Chen Lei. Old-age security from the perspective of demand of urban empty nest elderly home pension service model. 2010,03:155-159. 